\title{
Is vitamin D deficiency a feature of pediatric celiac disease?
}

\author{
Jeffrey Villanueva ${ }^{1}$, Louise Maranda ${ }^{2}$ and \\ Benjamin Udoka Nwosu ${ }^{2, *}$ \\ ${ }^{1}$ University of Massachusetts Medical School, Worcester, \\ MA, USA \\ ${ }^{2}$ University of Massachusetts Medical School - Pediatrics, \\ Worcester, MA, USA
}

\begin{abstract}
Background: Celiac disease (CD) is an autoimmune enteropathy characterized by villus atrophy and malabsorption of essential nutrients. Vitamin D deficiency has been described in autoimmune diseases, but its status in prepubertal children with $\mathrm{CD}$ has not been adequately studied.

Objective: To determine the vitamin D status of prepubertal children with $\mathrm{CD}$.

Study design: A retrospective study of prepubertal children aged 3-12 years with $C D(n=24)$ who were compared to prepubertal, non-CD children of the same age $(n=50)$. Children were included in the study if they had a diagnosis of $\mathrm{CD}$ by intestinal biopsy, and were not on a gluten-free diet (GFD). Patients were excluded if they had diseases of calcium or vitamin D metabolism, or were receiving calcium or vitamin D supplementation or had other autoimmune diseases. All subjects had their serum 25-hydroxyvitamin D [25(OH)D] level measured.
\end{abstract}

Results: There was no difference in $25(\mathrm{OH}) \mathrm{D}$ level between the $\mathrm{CD}$ and non-CD children (27.58 \pm 9.91 vs. $26.20 \pm 10.45$, $\mathrm{p}=0.59$ ). However, when the patients were subdivided into obese and non-obese groups, the non-obese CD patients had a significantly higher $25(\mathrm{OH}) \mathrm{D}$ level than the obese normal children $(28.39 \pm 10.26$ vs. $21.58 \pm 5.67, \mathrm{p}=0.009)$. In contrast, there was no difference in $25(\mathrm{OH}) \mathrm{D}$ level between non-obese $\mathrm{CD}$ patients and non-obese normal children (28.39 \pm 10.26 vs. $30.64 \pm 12.08, \mathrm{p}=0.52)$. The season of $25(\mathrm{OH}) \mathrm{D}$ measurement was not a significant confounder $(\mathrm{p}=0.7)$.

Conclusions: Our data showed no difference in $25(\mathrm{OH})$ $D$ levels between normal children and those with $C D$ when adjusted for body mass index.

Keywords: celiac disease; children; prepubertal status; vita$\min \mathrm{D}$.

\footnotetext{
*Corresponding author: Benjamin Udoka Nwosu, Division of Endocrinology, Department of Pediatrics, University of Massachusetts Medical School, 55 Lake Avenue North Worcester, MA 01655, USA

Phone: +1-508-334-7872, Fax: +1-508-856-4287,

E-mail: benjamin.nwosu@umassmemorial.org

Received January 15, 2012; accepted March 10, 2012;

previously published online April 21, 2012
}

\section{Introduction}

Celiac disease (CD) is an autoimmune enteropathy that affects $0.5-1 \%$ of the population (1). It is characterized by villus atrophy and malabsorption of essential nutrients. The pathogenesis of $\mathrm{CD}$ is based on a combination of genetic and environmental factors (2). The most important predisposing genetic factors to CD are HLA-DQ2 and HLA-DQ8 molecules (3). There is a 70\% concordance for $\mathrm{CD}$ in monozygotic twins (2). Environmental factors, such as the time of initial exposure of intestinal epithelium to gluten (4), as well as the duration of gluten exposure are also associated with the development of CD (5).

Gluten is a protein component in wheat, rye and barley. The toxicity associated with these proteins is related to glutamine and proline-rich amino acid sequences (2). An immune response, mostly within the lamina propria, leads to the release of tissue transglutaminase from inflamed cells (2). Tissue transglutaminase is an intracellular enzyme that can interact with glutamine and proline-rich proteins, such as those in gluten (2). These interactions can generate new antigens that are targeted by immunoglobulin A fraction in patients who are genetically predisposed to develop $\mathrm{CD}$. Tissue transglutaminase enzyme, an autoantigen in $\mathrm{CD}$ (6) deamidates gluten peptides leading to increased immunoreactivity of the gluten peptides (7). The small bowel damage from activated CD $8+$ cells is characterized histologically by an invasion of lymphocytes into the epithelium and lamina propria, progression to crypt hyperplasia, and finally to blunting of intestinal villi (2). Resolution of these intestinal lesions can occur after the removal of the inciting proteins from the susceptible individual's diet $(8,9)$. Untreated $\mathrm{CD}$, however, is associated with malnutrition in $67 \%$ of patients (10). Interestingly, obesity has been reported in children with $\mathrm{CD}$ at a prevalence rate of 5\% (11).

The role of intestinal epithelial damage on vitamin D absorption in prepubertal children with $\mathrm{CD}$ has not been fully studied. Vitamin D receptors are present in the crypts of CD intestine, and it is unclear whether the intestinal inflammation of $\mathrm{CD}$ leads to malabsorption of fat-soluble vitamins, and consequent vitamin D deficiency (12). Vitamin D deficiency has been reported in related autoimmune diseases, such as type 1 diabetes mellitus and chronic lymphocytic thyroiditis $(13,14)$, which are frequently seen in patients with CD (14). Some investigators have speculated that the intestinal damage in $\mathrm{CD}$ could result in vitamin $\mathrm{D}$ malabsorption and vitamin D deficiency $(9,10)$. Lerner et al (3) studied two cohorts of patients with CD living in two sunny countries, Israel and Spain, and found that serum concentrations of vitamin D is negatively correlated with age, but not with the degrees of intestinal damage. However, the vitamin D metabolism in prepubertal children with $\mathrm{CD}$ in cold climates has not been fully studied. This is important because even though children 
in both cold and sunny climates may have a similar degree of villus atrophy, the increased exposure to ultraviolet radiation in sunny countries could easily lead to normal vitamin D levels in children in contrast to children living in colder climates with limited exposure to ultraviolet radiation.

Therefore, to bridge this knowledge gap, we designed this study with the primary aim of determining whether vitamin $D$ insufficiency is a feature of CD in prepubertal children living in cold climates along $42^{\circ} \mathrm{N}$. Our hypothesis was that $\mathrm{CD}$ children would have low vitamin D levels compared to healthy children. To examine this hypothesis we conducted a retrospective chart review of children with $\mathrm{CD}$ who had $25(\mathrm{OH}) \mathrm{D}$ measured, and compared this group to a cohort of healthy prepubertal children who participated in a prospective cross-sectional study on the role of vitamin D metabolism on bone mineral content (clinical trial identifier NCT00756899).

\section{Study participants}

We reviewed the medical records of prepubertal children aged 3-12 years with $\mathrm{CD}$ at the Children's Medical Center of the Umass Memorial Medical Center between 2008 and 2011. The study protocol was approved by the University of Massachusetts Institutional Review Board. Study subjects $(\mathrm{n}=24 ; 15$ females and nine males) were included if they had a diagnosis of $\mathrm{CD}$, had $25(\mathrm{OH}) \mathrm{D}$ level measured at diagnosis, were not on gluten-free diet (GFD), and were not taking vitamin D or calcium supplementation. Patients were excluded if they had diseases of calcium or vitamin D metabolism or had other autoimmune diseases. Diagnosis of CD was based upon upper gastrointestinal biopsies consistent with $\mathrm{CD}$ clinical presentation. Age was determined by the date of $25(\mathrm{OH}) \mathrm{D}$ measurement. Subjects were categorized into non-obese and obese categories, using a body mass index (BMI) of $>95$ th percentile to define obesity (15).

A group of 50 age-matched healthy prepubertal children who participated in a cross-sectional study entitled 'The Relationship between Vitamin D Deficiency and Low Bone Mineral Content in Children', ClinicalTrials.gov Identifier: NCT00756899, at the Children's Medical Center of the Umass Memorial Medical Center, served as normal controls. All subjects in the control group were prepubertal, had no diagnosis of $\mathrm{CD}$, and were not on vitamin $\mathrm{D}$ or calcium supplementation. They had no medical diseases affecting calcium or vitamin $\mathrm{D}$ metabolism. Their age was determined by the date of $25(\mathrm{OH}) \mathrm{D}$ measurement. This group consisted of 25 obese and 25 non-obese subjects.

\section{Anthropometry}

Height was measured to the nearest $0.1 \mathrm{~cm}$ using a wallmounted stadiometer (Holtain Ltd, Crymych, Dyfed, UK). Weight was measured to the nearest $0.1 \mathrm{~kg}$ using an upright scale. BMI was derived using the formula weight $/$ height $^{2}$ $\left(\mathrm{kg} / \mathrm{m}^{2}\right)$, and expressed as standard deviation score (SDS) for age and gender based on National Center for Health Statistics (NCHS) data (16).

\section{Assays}

The $25(\mathrm{OH}) \mathrm{D}$ was assayed by chemiluminescence immunoassay which has $100 \%$ cross-reactivity with both vitamin $\mathrm{D}_{2}$ (the plant-derived form of vitamin D called ergocalciferol) and $\mathrm{D}_{3}$ (the animal derived form known as cholecalciferol). The immunoassay detects total body $25(\mathrm{OH}) \mathrm{D}$ content. Its functional sensitivity is $4 \mathrm{ng} / \mathrm{mL}(10 \mathrm{nmol} / \mathrm{L})$, and its intra- and inter-assay coefficients of variation are $5 \%$ and $8.2 \%$, respectively. Vitamin D deficiency was defined as a $25(\mathrm{OH}) \mathrm{D}$ level of $<15 \mathrm{ng} / \mathrm{mL}$, (37.5 nmol/L), vitamin D insufficiency as vitamin D level of $15-20 \mathrm{ng} / \mathrm{mL},(37.5-50 \mathrm{nmol} / \mathrm{L})$, and vitamin D sufficiency as $25(\mathrm{OH}) \mathrm{D}$ of $>20,100 \mathrm{ng} / \mathrm{mL},(50-250 \mathrm{nmol} / \mathrm{L})$ based on Pediatric Endocrine Society guidelines (17).

\section{Statistics}

Statistical analyses were performed using the SPSS Predictive Analytics SoftWare version19 (IBM Corporation, Somers, NY, USA). Means and standard deviations were calculated for descriptive summary statistics. Anthropometrics and $25(\mathrm{OH})$ D levels were compared using Student's t-test. Seasons were compared using Fisher's exact test. BMI was expressed as a standard deviation score (SDS).

\section{Results}

The baseline characteristics of the study patients and controls are shown in Table 1. There was no difference in mean 25(OH)D level between the $\mathrm{CD}$ and non-CD children (27.58 \pm 9.91 vs. $26.20 \pm 10.45, p=0.59)$. However, when the patients were subdivided into obese and non-obese groups, the non-obese $\mathrm{CD}$ patients had a significantly higher mean $25(\mathrm{OH}) \mathrm{D}$ level than the obese normal children $(28.39 \pm 10.26$ vs. $21.58 \pm 5.67, \mathrm{p}=0.009$ ) (Figure 1). In contrast, there was no difference in mean 25(OH)D level between non-obese CD patients and non-obese normal children $(28.39 \pm 10.26$ vs. $30.64 \pm 12.08, \mathrm{p}=0.52)$. Similarly, there was no difference in BMI SDS between non-obese CD patients and nonobese normal children $(-0.03 \pm 1.28$ vs. $0.03 \pm 1.12, \mathrm{p}=0.87)$. Mean BMI SDS differed significantly between obese normal children and non-obese normal children $(2.54 \pm 0.87$ vs. $0.03 \pm 1.12 \mathrm{p}<0.001)$; and also between obese normal children and non-obese CD patients ( $2.54 \pm 0.87$ vs. $-0.03 \pm 1.28$ $\mathrm{p}<0.001)$. The seasonality of $25(\mathrm{OH}) \mathrm{D}$ measurement was not a significant confounder $(\mathrm{p}=0.70)$.

\section{Discussion}

We found no difference in mean 25(OH)D levels between normal children and those with CD when adjusted for BMI. We also found that obese children in general had lower vitamin D levels compared to non-obese children.

Our finding is similar to other reports on vitamin D metabolism in CD $(3,9)$. Lerner et al (3) conducted a transcontinental study involving groups of children and adults with 
Table 1 Comparison of the characteristics of children with celiac disease and those of normal children.

\begin{tabular}{|c|c|c|c|c|c|c|}
\hline \multirow{2}{*}{$\frac{\text { Parameters }}{\text { Number }}$} & \multicolumn{3}{|c|}{ Celiac disease patients } & \multicolumn{3}{|c|}{ Normal controls } \\
\hline & All 24 & Obese 6 & Non-obese 18 & All 50 & Obese 25 & Non-obese 25 \\
\hline Age, year & $9.42 \pm 2.80$ & $10.31 \pm 2.61$ & $9.12 \pm 2.87$ & $8.02 \pm 2.66$ & $8.48 \pm 2.55$ & $7.56 \pm 2.73$ \\
\hline Sex, males & 9 & 2 & 7 & 29 & 16 & 13 \\
\hline Height SDS & $-0.64 \pm 1.32$ & $-0.87 \pm 1.97$ & $-0.56 \pm 1.10$ & $0.21 \pm 1.71$ & $0.96 \pm 1.51$ & $-0.55 \pm 1.57$ \\
\hline Weight SDS & $0.06 \pm 1.45$ & $1.43 \pm 0.63$ & $-0.39 \pm 1.36$ & $1.08 \pm 1.96$ & $2.55 \pm 1.04$ & $-0.03 \pm 1.12$ \\
\hline BMI SDS & $0.47 \pm 1.42$ & $1.97 \pm 0.27$ & $-0.03 \pm 1.28$ & $1.29 \pm 1.61$ & $2.54 \pm 0.87$ & $0.03 \pm 1.12$ \\
\hline $25(\mathrm{OH}) \mathrm{D}, \mathrm{ng} / \mathrm{mL}$ & $27.58 \pm 9.91$ & $25.17 \pm 9.17$ & $28.39 \pm 10.26$ & $26.20 \pm 10.45$ & $21.58 \pm 5.67$ & $30.64 \pm 12.08$ \\
\hline Seasons (summer+autumn) & 11 & 4 & 7 & 17 & 8 & 9 \\
\hline
\end{tabular}

25(OH)D, 25-hydroxyvitamin D; BMI, body mass index; SDS, standard deviation score.

$\mathrm{CD}$ to determine the effect of $\mathrm{CD}$ on vitamin $\mathrm{D}$ metabolism. They found no evidence of vitamin D deficiency in their pediatric patients. In contrast, they found significant vitamin D deficiency in their adult population. They explained that this discrepancy could be caused by the fact that children with $\mathrm{CD}$ have increased dietary intake of vitamin $\mathrm{D}$, are routinely supplemented with vitamin D in the first year of life, have more exposure to sunlight, and are more compliant with a gluten-free diet compared to adult CD patients. Thus, despite the malabsorptive state in $\mathrm{CD}$, vitamin $\mathrm{D}$ deficiency is not a feature of pediatric $C D$ as vitamin $D$ status may be unrelated to the degree of small bowel injury in CD (9). A possible reason for the lack of vitamin D deficiency in children with CD is that a majority of the hormone is produced in the skin upon exposure to ultraviolet radiation (18). Therefore, body stores might depend more on endogenous production rather than gastrointestinal absorption.

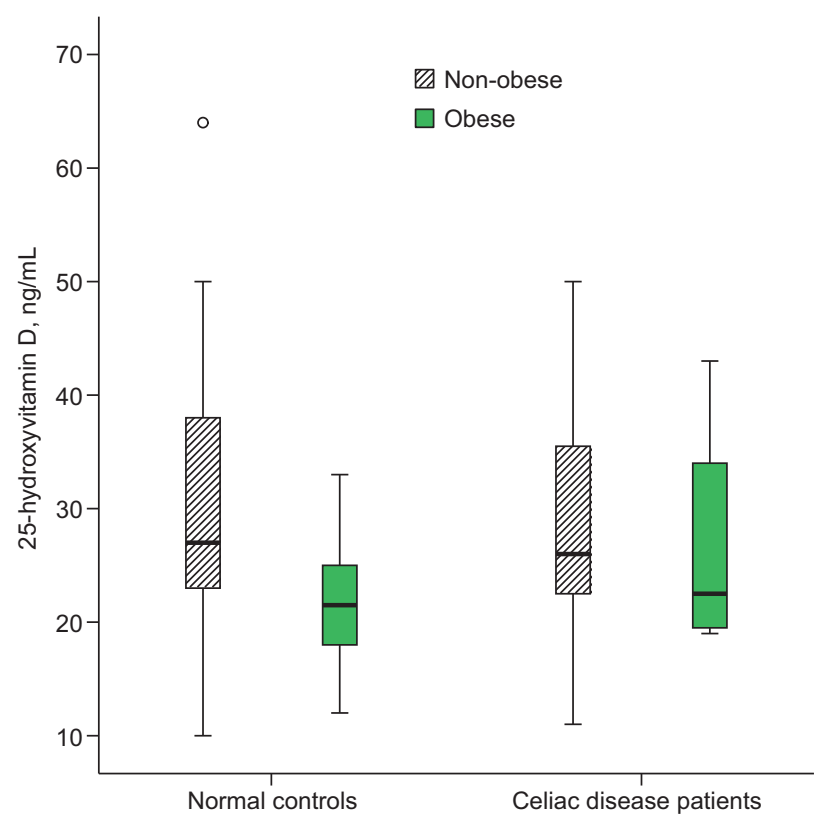

Figure 1 Box plots of the comparison of serum concentrations of 25-hydroxyvitamin D in patients with celiac disease and normal controls stratified by body mass index.
Our finding that obese children had lower vitamin D levels compared to non-obese children is consistent with previous reports on the relationship between $25(\mathrm{OH}) \mathrm{D}$ and BMI (19-22). The proposed reasons for vitamin D deficiency in the obese state include sequestration of vitamin $\mathrm{D}$ in excess body fat, negative feedback from an elevated 1-25dihydroxyvitamin D level, poor diet, or an avoidance of sunlight (20-22).

One of the limitations of our study is its cross-sectional design, which makes it difficult to establish temporality in 25(OH)D levels. Secondly, our results cannot be generalized because our patients were all residing in central Massachusetts, located at $42^{\circ} \mathrm{N}$, a geographical zone that receives insufficient amounts of ultraviolet radiation in the winter months for adequate skin synthesis of vitamin D. However, the blood samples for the study parameters were collected at different seasons of the year. We also had a smaller sample size for the CD patients compared to non-CD cohort. For example, we had only six obese patients with $C D$. Such a sample size would be inadequate to detect subtle differences between the groups and could have resulted in type 2 error. However, the proportion of obese patients with CD in our cohort is consistent with the $5 \%$ prevalence rate of obesity in the pediatric CD population (11). In contrast, we had a representative number of patients in the non-obese groups for the $\mathrm{CD}$ and non-CD cohorts to accurately assess the effects of $\mathrm{CD}$ on vitamin $\mathrm{D}$ metabolism in this subset of patients. This group of patients was of primary interest for this study because we specifically wanted to exclude the influence of obesity on vitamin $\mathrm{D}$ metabolism. The strengths of this study include the fact that we studied only prepubertal children, thus eliminating the effects of hormonal fluctuations associated with pubertal maturation on vitamin D metabolism. We also employed a representative group of control subjects in both the obese and non-obese cohorts. Finally, we provided a much-needed balance to Lerner's study (3) by investigating the vitamin D profiles of children with $\mathrm{CD}$ residing in cold climates.

In conclusion, our data show that vitamin D deficiency is not a feature of CD in prepubertal children living in cold climates. This is consistent with an earlier study in sunny climates which showed normal vitamin D levels in children with $\mathrm{CD}$. Therefore, children with $\mathrm{CD}$ do not require aggressive vitamin D supplementation. 


\section{Acknowledgments}

This study was supported in part by a grant to Benjamin U. Nwosu from the Department of Pediatrics, and the Faculty Diversity Scholars Program, University of Massachusetts Medical School, Worcester, MA. BUN is a member of the UMass Diabetes and Endocrine Research Center (DK32520).

\section{References}

1. Fasano A. Should we screen for coeliac disease? Yes. Br Med J 2009;339:b3592.

2. Schuppan D. Current concepts of celiac disease pathogenesis. Gastroenterol 2000;119:234-42.

3. Lerner A, Shapira Y, Agmon-Levin N, Pacht A, Ben-Ami Shor D, et al. The clinical significance of $25 \mathrm{OH}$-vitamin D status in celiac disease. Clin Rev Allergy Immunol 2011 Jan 7. [Epub ahead of print].

4. Weile B, Cavell B, Nivenius K, Krasilnikoff PA. Striking differences in the incidence of childhood celiac disease between Denmark and Sweden: a plausible explanation. J Pediatr Gastroenterol Nutr 1995;21:64-8.

5. Fasano A, Berti I, Gerarduzzi T, Not T, Colletti RB, et al. Prevalence of celiac disease in at-risk and not-at-risk groups in the United States: a large multicenter study. Arch Intern Med 2003;163:286-92.

6. Dieterich W, Ehnis T, Bauer M, Donner P, Volta U, et al. Identification of tissue transglutaminase as the autoantigen of celiac disease. Nat Med 1997;3:797-801.

7. van de Wal Y, Kooy Y, van Veelen P, Peña S, Mearin L, et al. Selective deamidation by tissue transglutaminase strongly enhances gliadin-specific T cell reactivity. J Immunol 1998;161: 1585-8.

8. Farrell RJ, Kelly CP. Celiac sprue. N Engl J Med 2002;346: $180-8$.

9. Mager DR, Qiao J, Turner J. Vitamin D and K status influences bone mineral density and bone accrual in children and adolescents with celiac disease. Eur J Clin Nutr. 2011 Oct 5. doi: 10.1038/ ejcn.2011.176. [Epub ahead of print].
10. Corazza GR, Di Sario A, Sacco G, Zoli G, Treggiari EA, et al. Subclinical coeliac disease: an anthropometric assessment. J Intern Med 1994;236:183-7.

11. Venkatasubramani N, Telega G, Werlin SL. Obesity in pediatric celiac disease. J Pediatr Gastroenterol Nutr 2010;51: 295-7.

12. Colston KW, Mackay AG, Finlayson C, Wu JC, Maxwell JD. Localisation of vitamin $\mathrm{D}$ receptor in normal human duodenum and in patients with coeliac disease. Gut 1994;35:1219-25.

13. Haroon M, Fitzgerald O. Vitamin D and its emerging role in immunopathology. Clin Rheumatol 2012;31:199-202.

14. Tamer G, Arik S, Tamer I, Coksert D. Relative vitamin D insufficiency in Hashimoto's thyroiditis. Thyroid 2011;21: 891-6.

15. Barlow SE. Expert committee recommendations regarding the prevention, assessment, and treatment of child and adolescent overweight and obesity: summary report. Pediatrics 2007;120 (Suppl. 4):S164-92.

16. Kuczmarski RJ, Ogden CL, Guo SS, Grummer-Strawn LM, Flegal KM, et al. 2000 CDC growth charts for the United States: methods and development. Vital Health Stat 2002;11: $1-190$.

17. Misra M, Pacaud D, Petryk A, Collett-Solberg PF, Kappy M. Vitamin D deficiency in children and its management: review of current knowledge and recommendations. Pediatrics 2008;122:398-417.

18. Norris JM. Can the sunshine vitamin shed light on type 1 diabetes? Lancet 2001;358:1476-8.

19. Olson ML, Maalouf NM, Oden JD, White PC, Hutchison MR. Vitamin D deficiency in obese children and its relationship to glucose homeostasis. J Clin Endocrinol Metab 2012;97: 279-85.

20. Bell NH, Epstein S, Greene A, Shary J, Oexmann MJ, et al. Evidence for alteration of the vitamin D-endocrine system in obese subjects. J Clin Invest 1985;76:370-3.

21. Wortsman J, Matsuoka LY, Chen TC, Lu Z, Holick MF. Decreased bioavailability of vitamin D in obesity. Am J Clin Nutr 2000;72:690-3.

22. Compston JE, Vedi S, Ledger JE, Webb A, Gazet JC, et al. Vitamin D status and bone histomorphometry in gross obesity. Am J Clin Nutr 1981;34:2359-63. 